WHOI-84-4

Undersea Acoustic Research

by

Robert C. Spindel

Principal Investigator

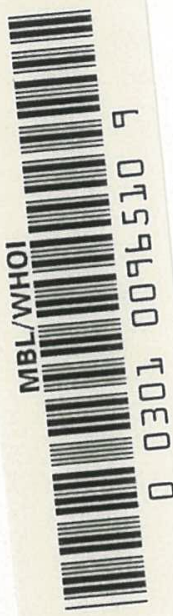

Woods Hole Oceanographic Institution

Woods Hole, Massachusetts 02543

January 1984

Technical Report

Funding was provided by the Office of Naval Research under Contract N00014-77-C-0196.

Reproduction in whole or in part is permitted for any purpose of the United States Government. This report should be cited as: Woods Hole Oceanog. Inst. Tech. Rept. WHOI-84-4.

Approved for public release; distribution unlimited.

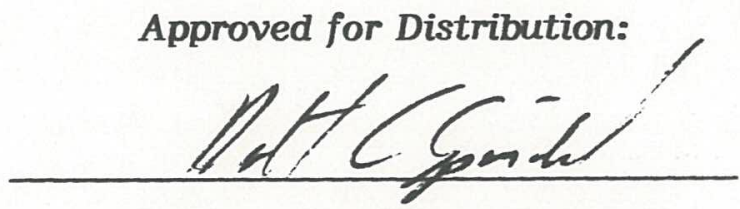

Robert C. Spindel, Chairman

Department of Ocean Engineering 


\section{UNDERSEA ACOUSTIC RESEARCH}

by

Robert C. Spindel, Principal Investigator

Woods Hole Oceanographic Institution

Woods Hole, Massachusetts 02543

January 1984

TECHNICAL REPORT 
ABSTRACT

This is the final report of Contract N00014-77-C-0196 between the Woods Hole Oceanographic Institution and the Office of Naval Research for the contract period I January 1977 to 28 February 1983. This contract supported a broad program of research and development in underwater acoustics related to present and future Navy systems and requirements.

The bulk of this contract research was conducted from 1977 to 1981, during which time the categories outlined below were all areas of active research. (Between 1981 and 1983 the contract remained in effect, although only in the area of bottom acoustics and at a reduced level.) The primary contract products are the published technical reports and papers listed below. These reports give detailed descriptions of the research work and the specialized techniques, methods, and instrumentation developed to support this research program.

The final report contains a brief review of the program highlights and a bibliography of associated reports. 


\section{TABLE OF CONTENTS}

INTRODUCTION

PROGRAM SUMMARIES

I. Acoustic Fluctuations 2

II. High Frequency Remote Sensing of the Near Surface Ocean 4

III. Ocean Acoustic Tomography - 6 Mapping of the Ocean Sound Speed Field

IV. Acoustic Properties of the Ocean Bottom 8

V. Sonar Array Processing 10

BIBLIOGRAPHY 11 
INTRODUCTION

This is a final report of the research and development activities conducted at the Woods Hole Oceanographic Institution under the auspices of the Office of Naval Research Contract NO0014-77-C-0196, during the period 1 January 1977 to 28 February 1983.

There has been a continuous series of underwater acoustics research programs at Woods Hole since the founding of ONR. The immediate predecessor to the present contract was Contract N00014-70-C-0205; NR 083-25 which ran from 1967 to 1976. The successor to this contract is Contract N00014-76-C-0152. It is presently in effect. Each change of contract has included transfer of equipment, reports and contractual obligations. Most changes have also included the initiating of new research programs.

The major objective of this series of contracts has been to devise analytic and experimental methods to enhance the application of acoustics to Navy missions and systems. The general direction of the work has been guided by perceived Navy needs. During the present five year contract period, we have worked on a wide variety of problems including:

(1) the fluctuations in low frequency acoustic signals that are transmitted long distances underwater due to multipath and internal oceanic processes;

(2) the acoustic remote sensing of near surface phenomena such as mixing processes and internal waves, as well as the distribution of natural and man-made suspended particles;

(3) the development of in situ, microprocessor controlled sources and receivers for long term data collection; 
(4) the development of the technique of acoustic ocean tomography for remote sensing of the sound speed field in an ocean volume;

(5) the detection and estimation problems associated with passive acoustic arrays and the localization and tracking of both narrowband and wideband sources;

(6) the development of a variety of theoretical and empirical techniques aimed at measuring the complete, complex acoustic reflection coefficient of the ocean bottom.

In addition to these areas of research and development, we have frequently served in an advisory capacity to a variety of Navy activities. These have included representation on Navy panels and committees concerned with oceanographic and acoustic problems such as towed array systems, mine search and defense, ambient noise, signal coherence, and seismic signal detection. Discussions with FNOC, NRL, NOSC, NUSC, NORDA, NAVOCEANO, SACLANT, COMOCEANSYSLANT, NADC, NAVSEA, various project management offices, and others have occurred on a continuing basis.

The following paragraphs are brief summaries of the major areas of focus under this contract. Pertinent reports and other published material are listed for each area.

\section{PROGRAM SUMMARIES}

\section{Acoustic Fluctuations}

The basic issues addressed here involved the causes and magnitude of the variations and fluctuations observed in low frequency ( $<500 \mathrm{~Hz}$ ) acoustic signals transmitted to long ranges (100 to 1000 's of $\mathrm{km}$ ). Remote, in situ, moored acoustic sources and receivers and an acoustic navigation technique 
based on Doppler shifts and phase measurements were developed to conduct a series of at sea field exercises. Relationships between acoustic fluctuations and multipath interference and internal wave dynamics were established.

\section{Bibliography}

R.P. Porter and R.C. Spindel, "Low frequency acoustic fluctuations and internal gravity waves in the ocean," J. Acoust. Soc. Am. 61, 943-950, 1977.

Robert P. Porter and Robert C. Spindel, "Statistics of low frequency multipath tluctuations in the ocean," J. Acoust. Soc. Am. 64, 269-279, 1978.

R.C. Spindel, "Acoustic fluctuations," Proc. Acoust. Fluc. Workshop, NRL, 1977.

R.C. Spindel, "Acoustic navigation," Oceans 20, 22-29, 1977.

Robert C. Spindel, Kenneth R. Peal, Donald E. Koelsch, "A microprocessor acoustic data buoy," IFEE Oceans '78, 527-537, 1978.

R.C. Spindel, R.P. Porter, and J.A. Schwoerer, "Acoustic phase tracking of ocean moorings," IEEE J. Oceanic Engineering, OE-3, 27-30, 1978.

K.C. Spindel, R.P. Porter and D.C. Webb, "A mobile coherent low-frequency acoustic range," IEEE J. Oceanic Eng., O.E.-2, 331-337, 1977). 
II. High Frequency Remote Sensing of the Near Surface Ocean

This program employed high frequency acoustic echo sounding techniques to investigate near surface ocean mixing processes, internal wave dynamics, and the distribution of natural and man-made particulate matter. A series of field experiments was conducted with a specially designed sonar capable of yielding high resolution records over a wide range of frequencies (20 $\mathrm{KHz}$ to $5 \mathrm{MHz})$. Evidence of internal wave formation, of breaking, sewage plumes and other phenomena were obtained.

\section{Bibliography}

Frederick R. Hess and Marshall H. Orr, "Remote sensing of near surface oceanic mixing processes," EOS, Am. Geophys. Union, 59(12), 1978.

Marshall H. Orr and Frederick R. Hess, "Remote acoustic monitoring of natural suspensate distributions, active suspensate resuspension and slope shelf water intrusion," J. Geophys. Res. 83, 4062-4068, 1978.

Marshall H. Orr and Frederick R. Hess, "Remote sensing of internal waves, isopycnal surfaces and interleaving water masses in the vicinity of Hudson Canyon," EOS, Trans. Am. Geophys. Union, 59(12), 1978.

Marshall H. Orr and Frederick R. Hess, "Remote sensing of physical processes in the ocean using high-frequency acoustic backscattering systems," J. Acoust. Soc. Am. 65, (S104), 1978.

F.R. Hess and M.H. Orr, "A towed, multi-frequency H.F. sonar system for scattering and ocean dynamics studies," WHOI Technical Report No. WHOI-79-76, 27-32, 1979.

F.R. Hess and M.H. Orr, "A wide range sonar system for oceanic investigations," IFEE Proceedings of OCEANS 179, 27-32, 1979.

Marshall H. Orr, "Remote acoustic sensing of oceanic fluid and biological processes," WHOI Tech. Memo 80-2, 1980.

Marshall H. Orr, "Remote acoustic detection of predator-prey interaction, biological response to oceanographic instrumentation, and the response of biological organisms to fluid processes," Canadian Journal of Fisheries and Aquatic Sciences, 38, No. 9, 1096-1105, 1981. 
Marshall H. Orr, "Short period internal waves in Massachusetts Bay: development, decay and associated mixing processes," J. of Marine Research, 1982.

Marshall H. Orr and Lincoln Baxter II, "Seasonal dependence of the vertical and horizontal dispersion of particles formed or released during the disposal of industrial chemical wastes or sewage sludge," Proc. of the Second International Ocean Dumping Symposium, April 15-18, 1980.

Marshall H. Orr and Frederick R. Hess, "Detection of hydraulic jumps, internal waves, lee waves, and shear instabilities in the vicinity of the head of Hudson Canyon," Submitted to J. Fluid Mech., 1982. 
III. Ocean Acoustic Tomography - Mapping of the Ocean Sound Speed Field This portion of the program is an outgrowth of (I) above. Whereas in (I), we sought to establish the relationships between acoustic fluctuations and oceanic processes, here we exploit knowledge of the relationships to solve the inverse problem, i.e., we measure acoustic fluctuations and infer the underlying oceanic processes. Specifically, we measure the variation in acoustic travel time of pulses transmitted through the ocean volume to measure changes in the ocean's sound speed field. Sound speed is a function of temperature, salinity, and to a lesser extent, other dissolved chemical agents.

A suite of moored equipment was developed especially for this application. Acoustic sources and receivers, outgrowths of those developed in (I), transmitted and received phase coded pseudonoise sequences thereby allowing the resolution of single acoustic paths. Receivers contained microprocessors with sophisticated signal processing algorithms for data compression and storage. A pulsed acoustic navigation system for mooring motion measurement was developed.

The program culminated in a successful field test of ocean tomography in 1981 .

\section{Bibliography}

W. Munk, B. Zetler, J. Clark, S. Gill, D. Porter, J. Spiesberger, and R. Spindel, "Tidal effects on long-range sound transmission," JGR (Green) 86, 6399-6410, 1981.

J. Spiesberger, R. Spindel and K. Metzger, "Stability and identification of ocean acoustic multipaths," J. Acoust. Soc. Am. 67, 2011-2017, 1980.

R.C. Spindel, "An underwater acoustic pulse compression system," IFEE Trans. Acous. Speech and Sig. Proc., ASSP-27, 723-728, 1979. 
R.C. Spindel, "Multipath processing for ocean acoustic tomography," IEEE Electronics and Aerospace Systems Convention, EASCON '80, $80 \mathrm{CH}$ 1578-4AES, $165-170,1980$.

R.C. Spindel, "Ocean acoustic monitoring: acoustic tomography," Proc. Near Surface Ocean Experimental Technology Workshop, NORDA, NSTL Station, MS 39579, 219-233, 1980 .

R.C. Spindel, "Ocean acoustic tomography," Proc. Conf. Advances in Underwater Acoustics, Institute of Acoustics, Edinburgh, 3.1-3.11, 1981.

R.C. Spindel, "The 1981 ocean acoustic tomography experiment: preliminary results," J. Acoust. Soc. Am. (A) 71, 540, 1982.

R.C. Spindel, "Ocean acoustic tomography: a new measurement tool," Oceanus $25,12-21,1982$.

R.C. Spindel and W. Munk, "Ocean acoustic tomography: method, trials and plans," International Symposium on Underwater Acoustics, Tel-Aviv, Israel, 1981.

R.C. Spindel and J. Spiesberger, "Multipath variability due to the Gulf Stream," J. Acoust. Soc. Am. 69, 982-988, 1981.

R.C. Spindel, P. Worcester, D.C. Webb, P.R. Boutin, A.M. Bradley, and K.R. Peal, "Instrumentation for ocean acoustic tomography," IFEE Oceans '82, 82 CH1827-5, 92-99, 1982. 


\section{Acoustic Properties of the Ocean Bottom}

The purpose of this program is to develop methods and techniques for determining the acoustic properties of the ocean bottom. This knowledge is necessary for the accurate modelling and prediction of the acoustic field in the water column. In particular, analytic methods and experimental procedures were devised to measure the complex (both amplitude and phase) reflection coefficient of the ocean bottom. This information is essential for the full wave equation solution for the acoustic field (or for wave equation variants such as the parabolic equation). A deep (5000 m), towed, $200 \mathrm{~Hz}$ acoustic source and receiver system was developed for the field program. A number of signal processing algorithms were devised for data reduction and analysis.

\section{Bibliography}

George V. Frisk, "Inhomogeneous waves and the plane wave reflection coefficient," J. Acoust. Soc. Am. 66, 219-234, 1979.

George V. Frisk, "Determination of sediment sound speed profiles using caustic range information," Bottom-Interacting Ocean Acoustics, edited by W.A. Kuperman and F.B. Jensen (Plenum, New York, 1980).

George V. Frisk, Alan V. Oppenheim, and David R. Martinez, "A technique for measuring the plane wave reflection coefficient of the ocean bottom," J. Acoust. Soc. Am. 68, 602-612, 1980.

George V. Frisk, James A. Doutt, and Earl E. Hays, "Bottom interaction of low-frequency acoustic signals at small grazing angles in the deep ocean," J. Acoust. Soc. Am. 69, 84-94, 1981.

Nark K. Macpherson and George V. Frisk, "The contribution of normal modes in the bottom to the acoustic field in the ocean, "J. Acoust. Soc. Am. 68, 929-940, 1980 . 
Alan V. Oppenheim, George V. Frisk, David R. Martinez, "A technique for the evaluation of circularly symmetric two-dimensional Fourier transforms and its application to the measurement of ocean bottom reflection coefficients," in Digital Signal Processing, edited by V. Cappelini and A.G. Constantinides (Acađemic, New York, 1980).

Alan V. Oppenheim, George V. Frisk, and David R. Martinez, "Computation of the Hankel transform using the "Projection-Slice" theorem," J. Acoust. Soc. Am. $68,523-529,1980$. 
V. Sonar Array Processing

The objective of this program has been to devise efficient optimal and sub-optimal procedures for processing passive sonar array data for target location and trajectory. The work was directed towards distributed arrays or interarray processing at surveillance frequencies, although the findings apply to other cases as well. The effort was entirely analytic. The primary result was the development of a decentralized technique for nearly optimal target position and velocity estimation using the maximum likelihood estimator. This method results in very little degradation in performance, but achieves considerable savings in computer processing time and costs.

\section{Bibliography}

Peter M. Schultheiss and Ehud Weinstein, "Estimation of differential Doppler shifts," J. Acoust. Soc. of Am. 66, No. 55(5), 1412-1419, 1979.

Ehud Weinstein and Nadav Levanon, "Passive array tracking of a CW transmitting projectile," IEEE Transactions on Aerospace and Electronic Systems, Vol. AES-16, No. 5, 721-726, 1980.

Ehud Weinstein, "Decentralization of the Gaussian maximum likelihood estimator and its applications to passive array processing," IEEE Transactions on Acous. Speech and Sig. Proc., 945-951, 1981.

Ehud Weinstein, "Measurement of the differential Doppler shift," IEEE Transactions on Acoustics, Speech and Signal Processing, 112-117, 1982.

Ehud Weinstein, "Optimal source localization and tracking from passive array measurements," IEEE Trans. on Acoust., Speech and Sig. Proc. 69-76, 1982. 
BIBLIOGRAPHY

Published in 1977

R.C. Spindel, "Acoustic fluctuations," Proc. Acoust. Fluc. Workshop, NRL, 1977.

R.C. Spindel, "Acoustic navigation," Oceans 20, 22-29, 1977.

R.P. Porter and R.C. Spindel, "Low frequency acoustic fluctuations and internal gravity waves in the ocean," J. Acoust. Soc. Am. 61, 943-950, 1977.

R.C. Spindel, R.P. Porter and D.C. Webb, "A mobile coherent low-frequency acoustic range," IEEE J. Oceanic Eng., O.E.-2, 331-337, 1977.

Published in 1978

Frederick R. Hess and Marshall H. Orr, "Remote sensing of near surface oceanic mixing processes," EOS, Am. Geophys. Union, 59(12), 1978.

Alan V. Opvenheim, George V. Frisk, and David R. Martinez, "An algorithm for the numerical evaluation of the Hankel transform," Proc. IEEE 66, 264-265, 1978.

Marshall H. Orr and Frederick R. Hess, "Remote acoustic monitoring of natural suspensate distributions, active suspensate resuspension and slope shelf water intrusion," J. Geophys. Res. 83, 4062-4068, 1978.

Marshall H. Orr and Frederick R. Hess, "Remote sensing of internal waves, isopycnal surfaces and interleaving water masses in the vicinity of Hudson Canyon," EOS, Trans. Am. Geophys. Union, 59(12), 1978.

Marshall H. Orr and Frederick R. Hess, "Remote sensing of physical processes in the ocean using high-frequency acoustic backscattering systems," J. Acoust. Soc. Am. 65, (S104), 1978.

Robert P. Porter and Robert C. Spindel, "Statistics of low frequency multipath fluctuations in the ocean," J. Acoust. Soc. Am. 64, 269-279, 1978.

Robert C. Spindel, Kenneth R. Peal, Donald E. Koelsch, "A microprocessor acoustic data buoy," IEEE Oceans '78, 527-537, 1978.

R.C. Spindel, R.P. Porter, and J.A. Schwoerer, "Acoustic phase tracking of ocean moorings," IFEE J. Oceanic Engineering, OE-3, 27-30, 1978. 
Published in 1979

George V. Frisk, "Inhomogeneous waves and the plane wave reflection coefficient," J. Acoust. Soc. Am. 66, 219-234, 1979.

F.R. Hess and M.H. Orr, "A towed, multi-frequency H.F. sonar system for scattering and ocean dynamics studies," WHOI Technical Report No. WHOI-79-76, 27-32, 1979.

F.R. Hess and M.H. Orr, "A wide range sonar system for oceanic investigations," IEEE Proceedings of OCEANS '79, 27-32 1979.

Peter M. Schultheiss and Ehud Weinstein, "Estimation of differential Doppler shifts," J. Acoust. Soc. of Am. 66, No. 55(5), 1412-1419, 1979.

R.C. Spindel, "An underwater acoustic pulse compression system," IEEE Trans. Acous. Speech and Sig. Proc., ASSP-27, 723-728, 1979.

\section{Pulolished in 1980}

J.C. Beckerle, L. Baxter II, R.P. Porter, and R.C. Spindel, "Sound channel propagation through eddies southeast of the Gulf Stream," J. Acoust. Soc. Am. $68,1750-1767,1980$.

George V. Frisk, "Determination of sediment sound speed profiles using caustic range information," Bottom-Interacting Ocean Acoustics, edited by W.A. Kuperman and F.B. Jensen (Plenum, New York, 1980).

George V. Frisk, Alan V. Oppenheim, and David R. Martinez, "A technique for measuring the plane wave reflection coefficient of the ocean bottom," J. Acoust. Soc. Am. 68, 602-612, 1980.

Mark K. Macpherson and George V. Frisk, "The contribution of normal modes in the bottom to the acoustic field in the ocean," J. Acoust. Soc. Am. 68 , 929-940, 1980.

Alan V. Oppenheim, George V. Frisk, David R. Martinez, "A technique for the evaluation of circularly symmetric two-dimensional Fourier transforms and its application to the measurement of ocean bottom reflection coefficients," in Digital Signal Processing, edited by V. Cappelini and A.G. Constantinides (Academic, New York, 1980).

Alan V. Oppenheim, George V. Frisk, and David R. Martinez, "Computation of the Hankel transform using the "Projection-Slice" theorem," J. Acoust. Soc. Am. 68, 523-529, 1980 .

Marshall H. Orr, "Remote acoustic sensing of oceanic fluid and biological processes," WHOI Tech. Memo 80-2, 1980. 
Marshall H. Orr and Lincoln Baxter II, "Seasonal dependence of the vertical and horizontal dispersion of particles formed or released during the disposal of industrial chemical wastes or sewage sludge," Proc. of the Second International Ocean Dumping Symposium, April 15-18, 1980.

J. Spiesberger, R. Spindel and K. Metzger, "Stability and identification of ocean acoustic multipaths," J. Acoust. Soc. Am. 67, 2011-2017, 1980

R.C. Spindel, "Multipath processing for ocean acoustic tomography," IEEE Electronics and Aerospace Systems Convention, EASCON '80, $80 \mathrm{CH}$ 1578-4AES, 165-170, 1980.

R.C. Spindel, "Ocean acoustic monitoring: acoustic tomography," Proc. Near Surface Ocean Experimental Technology Workshop, NORDA, NSTL Station, MS 39579, 219-233, 1980 .

Ehud Weinstein and Nadav Levanon, "Passive array tracking of a CW transmitting projectile," IEEE Transactions on Aerospace and Electronic Systems, Vol. AE'S-16, No. 5, 721-726, 1980.

Published in 1981

George V. Frisk, James A. Doutt, and Earl E. Hays, "Bottom interaction of low-frequency acoustic signals at small grazing angles in the deep ocean," $J$. Acoust. Soc. Am. 69, 84-94, 1981.

W. Munk, B. Zetler, J. Clark, S. Gill, D. Porter, J. Spiesberger, and R. Spindel, "Tidal effects on long-range sound transmission," JGR (Green) 86, 6399-6410, 1981.

Marshall H. Orr, "Remote acoustic detection of predator-prey interaction, biological response to oceanographic instrumentation, and the response of biological organisms to fluid processes," Canadian Journal of Fisheries and Aquatic Sciences, 38, No. 9, 1096-1105, 1981.

R.C. Spindel, "Ocean acoustic tomography," Proc. Conf. Advances in Underwater Acoustics, Institute of Acoustics, Edinburgh, 3.1-3.11, 1981.

R.C. Spindel and W. Munk, "Ocean acoustic tomography: method, trials and plans," International Symposium on Underwater Acoustics, Tel-Aviv, Israel, June, 1981.

R.C. Spindel and J. Spiesberger, "Multipath variability due to the Gulf Stream," J. Acoust. Soc. Am. 69, 982-988, 1981.

Ehud Weinstein, "Decentralization of the Gaussian maximum likelihood estimator and its applications to passive array processing," IFEE Transactions on Acous. Speech and Sig. Proc., 945-951, October, 1981. 
Lincoln Baxter II and Marshall H. Orr, "Fluctuations in sound transmission through internal waves associated with the thermocline: a computer model for acoustic transmission through sound velocity fields calculated from thermistor chain CID, XBT, and acoustic backscattering," J. Acoust. Soc. Am. 71, 61-66, 1982 .

Marshall H. Orr, "Short period internal waves in Massachusetts Bay: development, decay and associated mixing processes," J. of Marine Research, 1982 .

Marshall H. Orr and Frederick R. Hess, "Detection of hydraulic jumps, internal waves, lee waves, and shear instabilities in the vicinity of the head of Hudson Canyon," Submitted to J. Fluid Mech., 1982.

R.C. Spindel, "The 1981 ocean acoustic tomography experiment: preliminary results," J. Acoust. Soc. Am. (A) 71, 540, 1982.

R.C. Spindel, "Ocean acoustic tomography: a new measurement tool," Oceanus 25, 12-21, Summer, 1982.

R.C. Spindel, P. Worcester, D.C. Webb, P.R. Boutin, A.M. Bradley, and K.R. Peal, "Instrumentation for ocean acoustic tomography," IEEE Oceans '82, 82 CH1827-5, 92-99, 1982.

Ehud Weinstein, "Measurement of the differential Doppler shift," IFEE Transactions on Acoustics, Speech and Signal Processing, 112-117, February, 1982 .

Ehud Weinstein, "Optimal source localization and tracking from passive array measurements," IFEE Trans. On Acoust., Speech and Sig. Proc. 69-76, February, 1982. 
Nađav Levanon and Ehud Weinstein, "Angle-independent Doppler velocity measurement," IEEE Transactions on Aerospace and Electronic Systems, June, 1983.

James F. Lynch, "On the use of focused horizontal arrays as mode separation and source location devices in ocean acoustics," J. Acoust. Soc. Am., 74(5), November, 1983.

James F. Lynch, "Some simple expressions for the beamforming properties of focused high resolution circular arrays, with applications to refocusing systems," J. Acoust. Soc. Am. 74(3), 847-850, September, 1983.

R.C. Spindel and Y.J.F. Desaubies, "Eddies and Acoustics," Eddies in Marine Science, edited by A.R. Robinson, (Springer-Verlag, 1983), 525-541. 


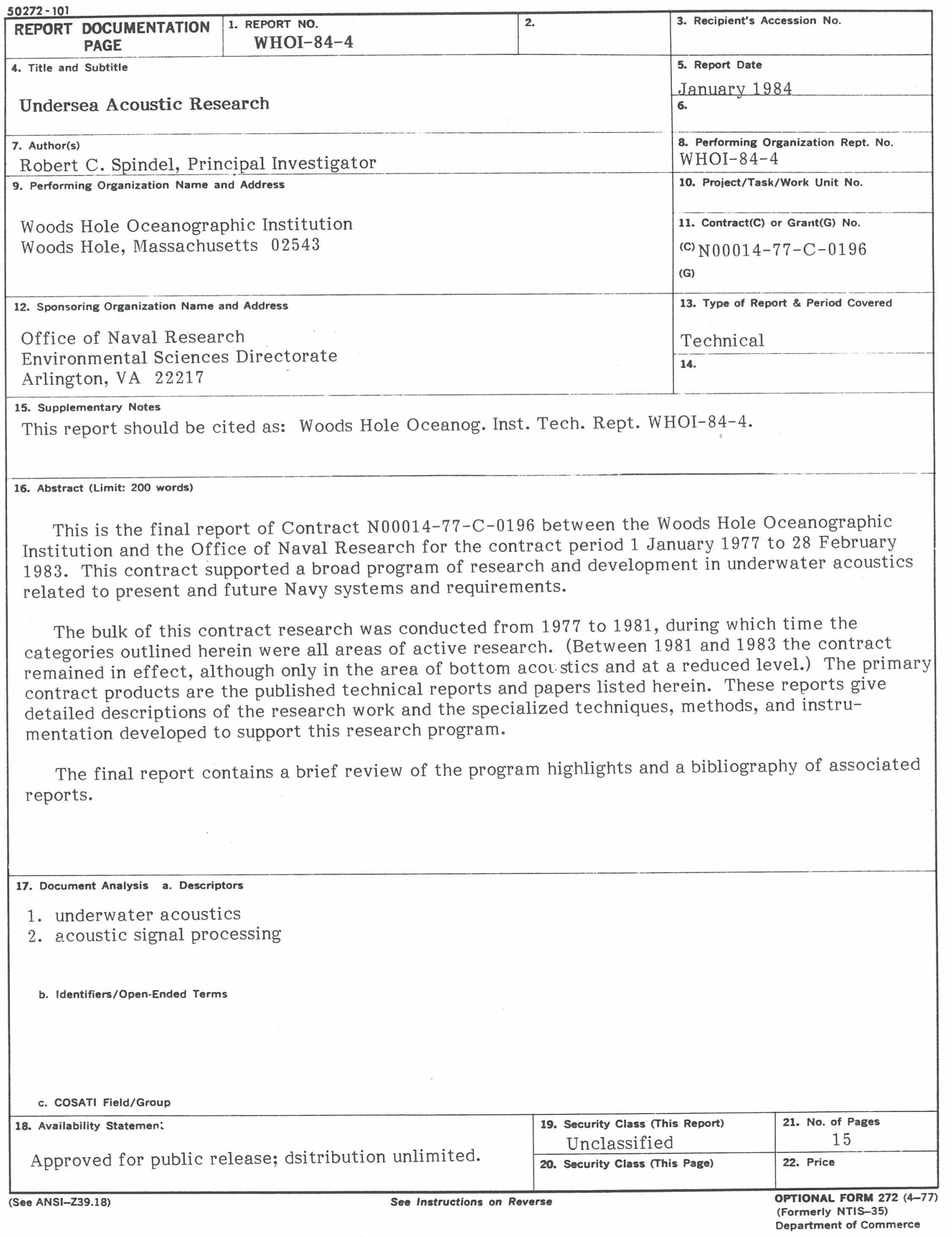


Director

Undersea Warfare Technology

Operational Application Division

Otfice of Naval Research

800 North Quincy Street

Arlington, Virginia 22217

Mike Kelly

Administrative Contracting Officer

Department of the Navy

Office of Naval Research

Eastern/Central Regional Office

495 Summer Street

Boston, MA 02210

Director

U.S. Naval Research Lab

Washington, DC 20390

Attn: Library, Code 2029 (ONRL)

Director

Code N0OO173

U.S. Naval Research Laboratory

Washington, DC 20390

Attn: - Technical Information Division

Defense Documentation Center

Building 5, Cameron Station

Alexandria, VA 22314

Technical Director

Code 110

NORLA:

National Space Technology Labs

SACLANT

Bay St. Louis, Mississippi 39529

Naval Research Laboratory

Code 2627

Washington, DC 20375

Chief of Naval Research

Office of Naval Research

Code 102IP

800 N. Quincy Street

Arlington, VA 22217 


\section{DISTRIBUTION CONTINUED}

WHOI: Dr. Robert C. Spindel

1 each

Dr. George Frisk

Dr. James Lynch

Dr. John Spiesberger

Dr. Ehud Weinstein

Mr. Frederick Hess

Mr. Donald Koelsch

Mr. Kenneth Peal 